\title{
HACIA UNA EDUCACIÓN PARA EL CONSUMO RESPONSABLE EN ITAPÚA-PARAGUAY
}

\section{Towards an education for responsible consumption in Itapúa-Paraguay}

\author{
Rosa María Vallejo De Cuella \\ Área Educación. Universidad Nacional de Itapúa (Paraguay) \\ Correo-e: rosacuellai@hotmail.com
}

Recibido: I6 de enero de 2020

Envío a informantes: 26 de enero de 2020

Aceptación definitiva: 30 de enero de 202I

Resumen: El artículo expone las experiencias institucionales y preceptos legales en cuanto a la Educación en Consumo en Itapúa-Paraguay, sobre qué es Consumir, acción propia, natural y vital para el ser vivo, y la necesidad existente de que las instituciones, como la Universidad Nacional de Itapúa, una de las principales del país, desde su función sustantiva que es la educación, en colaboración con otros organismos, brinden una mirada humana, educadora y formativa hacia el sector del consumidor, avalada en la experiencia de buenas prácticas en Consumo responsable de la Universidad de Salamanca-España, institución pionera en la comunidad autónoma, y de otras instituciones salmantinas que acompañan a los entes educativos y a la sociedad en materia de consumo.

Como resultado de un abordaje exploratorio-descriptivo se observa que la Ley I334/98 brinda un amparo legal a sus habitantes, que es una legislación bien enunciada pero poco divulgada, con una mayoría de ciudadanos en desconocimiento de sus derechos y deberes como también escaso compromiso de la mayoría de los municipios del país en adherirse al Sistema Nacional Integrado de Protección al Consumidor.

Esto demanda que la universidad sea centro de coordinación de actividades colaborativas interinstitucionales para el abordaje por medio de un diseño integral de Formación-Investigación-Extensión.

Palabras Clave: consumo; consumidor; educación para el consumo responsable; Formación-Extensión-Investigación. 
АвsтRAст: The article exposes the institutional experiences and legal precepts regarding Education Consumption Itapúa-Paraguay, on what is to consume, own, natural and vital for the living being action and the existing need for institutions such as the National University Itapúa, one of the largest in the country, from its substantive function is education, in collaboration with other agencies, can provide a human, educator and educational look into the consumer sector, backed by the experience of good practices in responsible Consumption University of Salamanca-Spain, pioneer in the autonomous community, and other Salamanca institutions accompanying educational authorities and consumer society.

As a result of an exploratory approach-descriptive observed that Law 1334/98 provides legal protection to its inhabitants, which is a well enunciated legislation but little known, with a majority of citizens know their rights and duties as little commitment most of the country's municipalities to join the Integrated National Consumer Protection System.

This demands that the university is focal point for collaborative activities interagency approach through a comprehensive design: Research-Training-Extension.

KEY WORDs: responsible consumption education; consumer; training-extension-research

\section{Introducción}

Apropiarse de la idea de Consumo responsable en Paraguay es un imperativo razonable; país inmerso en la fluida red global cuya población accede al uso de la tecnología, su crecimiento económico proviene de los sectores agroganadero, comerciales y de servicios, deberá en materia de consumo fortalecer acciones en cuanto a educación y difusión de la Ley I334 por medio de acciones colaborativas entre instituciones de carácter educativo, y las que tienen el compromiso de la defensa y protección de los consumidores, SEDECO-Municipios.

Existen hechos que interpelan a la acción a las instituciones, mismo por la dinámica social, el avance de los medios de comunicación, que, si bien es positivo, en algunos aspectos sobrepasa la formación de las personas en una sociedad de consumo. Tantas publicidades capturan el interés de la gente, con variedad de productos y servicios que se ofertan sin mayores barreras para cuantos quieran y puedan adquirirlos, esto muchas veces lleva a generar actitudes irresponsables de las personas, sea por desconocimiento o por falta de educación en el tema; a acceder a cuantas cosas les rodean, a veces hasta innecesarias, en detrimento de su propia economía, tranquilidad, generando daño al medio ambiente.

Como bien lo plantea Rosa María Pujol (1996, p, I6), consumir es una acción inherente a la humanidad desde sus orígenes. Supone un acto individual, pero a la vez es un fenómeno social. Y esos actos tanto particulares como sociales deben ir acompañados de una educación constante en pro de las personas y del medio que las rodea, porque vemos a las personas como hipnotizadas por tantas cosas a su alrededor que hasta se diría que cuesta establecer el equilibrio.

A esto se suma una sociedad poco informada, desde las instituciones que poseen el mandato de divulgación y educación en cuanto a lo que la ley plantea en defensa del consumidor; así mismo en los planes curriculares educativos de las instituciones de 
enseñanza formal el consumo es un tema escasamente considerado, salvo en algunos contenidos aislados.

El artículo presenta una propuesta de intervención que se plantea desde el ámbito de la Universidad Nacional de Itapúa, que contempla métodos y técnicas interinstitucionales que apuntan a la Educación como medio para el logro, en un futuro, de la práctica de un consumo responsable reproduciendo experiencias exitosas de instituciones y comunidades que han instalado en su colectivo social la cultura del consumo ético respetuoso con su medio.

El contexto considerado es Paraguay, país ubicado en América del Sur, con casi 7 millones de habitantes; dividido en 2 regiones naturales, la oriental y la occidental o Chaco. Itapúa es el $7 .^{\circ}$ departamento, localizado al sur del país; en él está asentada la Sede de la Universidad Nacional de Itapúa, creada por Ley Ioog/96, una de las principales universidades públicas del Paraguay, que lidera la educación superior en la región.

\section{Objetivos abordados}

a) Conocer de acciones llevadas adelante por la Universidad de Salamanca y el Ayuntamiento de Salamanca (España) en relación a la educación para el consumo responsable.

b) Describir acciones que la Secretaría de Defensa del Consumidor (SEDECO) y otras instituciones realizan en cuanto a Educación para el consumo en Itapúa-Paraguay en base a la Ley I334/98 y el abordaje de la UNI sobre el tema.

c) Proponer estrategias para que instituciones educativas, universitarias y no universitarias, gobiernos municipales, departamentales, empresas y colectivo social consideren la educación para el consumo responsable como un medio de desarrollo, de protección al ambiente, que favorece el bienestar social.

\section{Método}

El estudio es de diseño no experimental de alcance exploratorio-descriptivo, exploratorio por ser educación en consumo escasamente abordada; descriptivo por mostrar las dimensiones y el contexto situacional, de SEDECO, involucramiento de municipios, predisposición de la universidad, y conocimiento de los usuarios en cuanto a derechos y obligaciones; como también experiencias institucionales.

De enfoque mixto por la «riqueza interpretativa» y por su «mayor poder de entendimiento», en mayor grado lo cualitativo por la naturaleza del estudio.

Los datos, producto de entrevistas, encuestas, revisiones documentales de diversas fuentes, instituciones, sociedad de consumo y las experiencias, en particular, de la Universidad de Salamanca-España en educación, formación y proceder para el consumo responsable, sirven como base de propuesta del Plan de Desarrollo integrado para la Educación en consumo responsable.

El análisis situacional en materia de Consumo resultado de un FODA y el cuadro comparativo de España-Paraguay expone aspectos de orden legal, institucional y de formación respecto al consumo. 
Un muestreo no probabilístico, por conveniencia, fue la técnica aplicada para la selección de los contextos y de las unidades de análisis, considerando una población tipo cuyo resultado pueda generalizarse por sus características comunes con otra población (transferencia de resultados), la de Coronel Bogado, cuya densidad de población, flujo educativo, económico y financiero es similar a las de otros distritos donde están asentadas filiales de la UNI cuyos municipios no cuentan con oficina de atención al consumidor.

\section{Resultados}

Todos los datos aportados por los participantes han sido atendidos como relevantes, se han considerado casos adicionales que sirvieron para confirmar los resultados, chequeo con los participantes, a más de situaciones que son abiertamente evidentes (como la ausencia en 29 municipios de un total de 30 de la Oficina de Atención al consumidor, la no existencia en los currículos educativos de «Consumo» ni como tema transversal, solo disposiciones escuetas del Ministerio de Educación). Analizadas las informaciones considerando la problemática planteada, se procedió a la transferencia, Mertens (2010) citado por Sampieri ${ }^{\mathrm{T}}$ p. 458 donde parte de los resultados sirve para el planteamiento real de un Plan de Desarrollo.

\section{Breve diagnóstico situacional, visible desde el análisis FODA}

\begin{tabular}{|c|c|}
\hline FORTALEZAS & OPORTUNIDADES \\
\hline $\begin{array}{l}\text { Existencia de legislaciones claras relaciona- } \\
\text { das con el Consumo y el Cuidado del Medio } \\
\text { ambiente. } \\
\text { Instituciones responsables de la atención a } \\
\text { consumidores. } \\
\text { Experiencias de Municipios con Oficinas de } \\
\text { atención al consumidor. } \\
\text { Experiencia de Asociaciones de Consumi- } \\
\text { dores. } \\
\text { Consumo y producción sostenible, objetivos } \\
\text { del Desarrollo Sostenible de las NN. UU. }\end{array}$ & $\begin{array}{l}\text { Consumo responsable, tema escasamente } \\
\text { abordado por instituciones y organismos. } \\
\text { Instituciones educativas de todos los niveles } \\
\text { para el fomento de las campañas hacia un } \\
\text { Consumo responsable y de producción sos- } \\
\text { tenible. } \\
\text { Reconocimiento del MEC hacia los objetivos } \\
\text { del Desarrollo Sostenible. } \\
\text { Inclusión como líneas de Investigación sobre } \\
\text { Consumo y Producción en carreras univer- } \\
\text { sitarias. }\end{array}$ \\
\hline
\end{tabular}

Hernández Sampieri, R. (20I4) Metodología de la Investigación. Hace referencia al uso de los resultados de una investigación como Transferencia - traslado, donde pone de manifiesto la aplicabilidad de los resultados, no se refiere a generalizar los resultados a una población más amplia, sino que parte de ellos o su esencia puedan aplicarse en otros contextos (Savin-Baden y Major, 20I3; Morse, 20I2; y Williams, 20I5). Manifiesta Hernández Sampieri que resulta difícil que los resultados de una investigación cualitativa particular puedan transferirse a otro contexto, pero, en ciertos casos (donde se toma como caso aplicable el de la Educación para el consumo en Paraguay), pueden dar pautas para tener una idea general del problema estudiado y la posibilidad de aplicar ciertas soluciones en otro ambiente. 


\begin{tabular}{|c|c|}
\hline FORTALEZAS (cont.) & OPORTUNIDADES (cont.) \\
\hline $\begin{array}{l}\text { Voluntad de superiores jerárquicos de cen- } \\
\text { tros universitarios para el abordaje de la } \\
\text { Educación para el Consumo responsable. }\end{array}$ & $\begin{array}{l}\text { Población joven y con predisposición al vo- } \\
\text { luntariado y ganas de aprender. } \\
\text { Experiencias exitosas de instituciones uni- } \\
\text { versitarias y no universitarias extranjeras. }\end{array}$ \\
\hline DEBILIDADES & AMENAZAS \\
\hline $\begin{array}{l}\text { Insuficiencias presupuestarias institu- } \\
\text { cionales. } \\
\text { Escaso involucramiento de empresas en } \\
\text { campañas de información y formación } \\
\text { hacia el consumo responsable y produc- } \\
\text { ción sostenible. } \\
\text { Incipiente investigación sobre el tema. } \\
\text { Escasa formación de expertos en tema } \\
\text { Consumo. } \\
\text { Instituciones Municipales (Itapúa), en } \\
\text { su mayoría, no cuentan con Oficinas de } \\
\text { Defensa del Consumidor. De } 30 \text { solo I, } \\
\text { adherida al SNIPC. } \\
\text { Temática abordada de forma muy aisla- } \\
\text { da solo como breves contenidos, no vi- } \\
\text { sibilizados. }\end{array}$ & $\begin{array}{l}\text { Desinformación de los consumidores. } \\
\text { Incipiente campañas de Educación sobre } \\
\text { Consumo por las instituciones respon- } \\
\text { sables. } \\
\text { Mayor cantidad de publicidad de pro- } \\
\text { ductos y servicios, a campañas de con- } \\
\text { sumo responsable y producción soste- } \\
\text { nible. } \\
\text { Carencia de Educación para el Consu- } \\
\text { mo en los currículos de formación. } \\
\text { Globalización y escasa educación en va- } \\
\text { lores. }\end{array}$ \\
\hline
\end{tabular}

En Paraguay la Ley 1334/98, de Defensa del Consumidor y del Usuario, es la primera legislación que ampara a la persona como consumidor y usuario de bienes y servicios. La ley nombra al Ministerio de Industria y Comercio (MIC) como autoridad de aplicación; posteriormente, en el año 2013 se crea por Ley 4974/ız la Secretaría de Defensa del Consumidor (SEDECO), institución que pasa a administrar las disposiciones de la Ley i334 y demás leyes y reglamentos que rigen en la materia en el territorio nacional, y las mismas prerrogativas concede a las municipalidades que se adhieren al Sistema Nacional Integrado de Protección al Consumidor.

En el país existen 250 distritos con igual cantidad de Municipalidades, de las cuales 23 se hallan adheridas al sistema y no todas funcionan como plantea la Ley.

Figura i. Oficinas del Consumidor en territorios comunes con la UNI

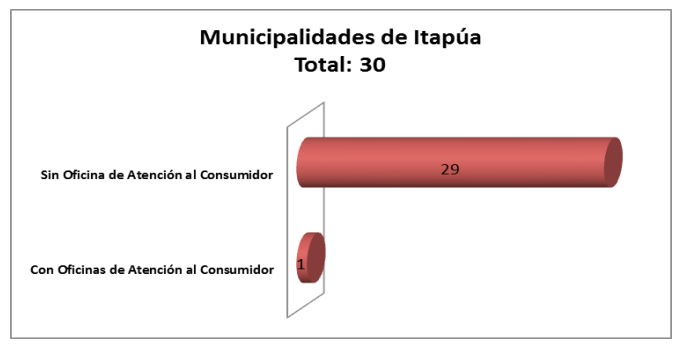


Esta valoración se refiere al territorio, donde la Universidad Nacional de Itapúa posee filiales, en el Departamento de Itapúa-Paraguay. Abarca 30 municipios de los cuales en 7 opera la UNI (Campus Central en Encarnación, luego el de Coronel Bogado, General Artigas, San Pedro del Paraná, Natalio, María Auxiliadora y Mayor Otaño), localizadas en el centro, sur y nordeste del departamento. Solo I, Encarnación, está adherido al SNIPC.

\section{Educación y formación, en materia de Consumo}

La materia educativa enfocada directamente para la Formación y Educación del Consumidor en aula es bastante escasa, se halla supeditada a la voluntad de directivos y docentes de centros de enseñanza, en el 2015 se extiende una circular por la cual el MEC solicita su abordaje en el aula ${ }^{2}$. Los docentes desconocen temáticas y técnicas relacionadas con el consumo, entonces mal se puede afirmar que lo abordan con sus estudiantes en el aula, cuando debería ser transversal desde las diferentes áreas del conocimiento, en todos los niveles, tanto en centros urbanos como rurales de gestión pública y privadas.

Esa formación debería darse no únicamente con una visión conceptual (Pujol, I996, p. 44), sino también procedimental, actitudinal; impulsar al alumnado a conocer la situación de consumo, analizar los temas planteados y asumir posturas son cuestiones fundamentales en la sociedad de consumo; ello supone a la vez recurso humano capacitado.

\footnotetext{
2 ww.mec.gov.py/Circular MEc. «Incorporación de los I7 objetivos en los planes de mejora educacional (con mención particular de los oDs 2030) en los consejos educativos departamentales, en las coordinaciones departamentales de supervisión, en las supervisiones educativas, en los proyectos educativos institucionales, en los proyectos curriculares institucionales y en los planes de aula». Los I7 objetivos: no pobreza, no hambre, buena salud, educación de calidad, igualdad de género, agua limpia y saneamiento, energía renovable, buenos trabajos y crecimiento económico, innovación e infraestructura, menos desigualdad, ciudad y comunidades sostenibles, consumo responsable, proteger el planeta, vida debajo del agua, vida en tierra firme, paz y justicia y sociedades para las metas.
} 


\begin{tabular}{|c|c|c|}
\hline \multicolumn{3}{|c|}{ COMPARATIVO DEFENSA DEL CONSUMIDOR Y USUARIO, desde 3 aspectos } \\
\hline Aspectos & ESPAÑA & PARAGUAY \\
\hline \multirow{4}{*}{ 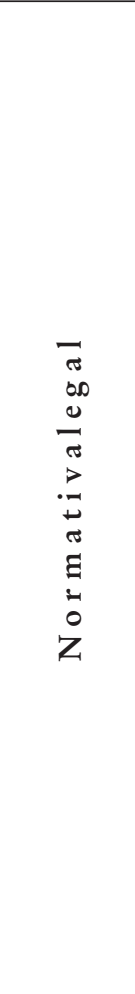 } & $\begin{array}{l}\text { Por Real Decreto Legislativo corresponde } \\
\text { al Estado administrar, promover y desarro- } \\
\text { llar la protección y defensa de los consumi- } \\
\text { dores y usuarios. }\end{array}$ & $\begin{array}{l}\text { Por Ley de la Nación ( } 1334 / 98) \text { se establece } \\
\text { la Defensa del Consumidor y Usuario, su } \\
\text { aplicación la realiza la Secretaría de Defensa } \\
\text { al consumidor y Usuario s/ Ley } 4974 / \mathrm{r} 3 \text {; el } \\
\text { Ministerio- (MIC) es autoridad de aplica- } \\
\text { ción a nivel nacional. }\end{array}$ \\
\hline & $\begin{array}{l}\text { Las comunidades autónomas por Estatutos } \\
\text { y Leyes orgánicas promueven y desarrollan } \\
\text { la defensa y protección al consumidor y } \\
\text { usuario. }\end{array}$ & $\begin{array}{l}\text { La Ley I334, menciona a los gobiernos de- } \\
\text { partamentales para la formulación de pla- } \\
\text { nes de educación para el consumo y el fo- } \\
\text { mento para la creación de asociaciones de } \\
\text { consumidores. } \\
\text { No menciona que deba promover la de- } \\
\text { fensa y protección del consumidor, ni que } \\
\text { pueda habilitar oficinas de atención. }\end{array}$ \\
\hline & $\begin{array}{l}\text { Los ayuntamientos, como corporación lo- } \\
\text { cal, promueven y desarrollan la defensa y } \\
\text { protección del consumidor de acuerdo a las } \\
\text { legislaciones del Estado y de las comunida- } \\
\text { des autónomas a las que pertenecen }\end{array}$ & $\begin{array}{l}\text { La Ley menciona a las Municipalidades } \\
\text { como organismos de aplicación de la Ley } \\
\text { a través del Sistema Nacional Integrado } \\
\text { de Protección al Consumidor, pero no las } \\
\text { obliga, es por adhesión voluntaria. }\end{array}$ \\
\hline & $\begin{array}{l}\text { La legislación posee un mandato nacional, } \\
\text { todas las comunidades autónomas y mu- } \\
\text { nicipios lo deben promover y desarrollar } \\
\text { la defensa y protección del consumidor y } \\
\text { usuario. }\end{array}$ & $\begin{array}{l}\text { La legislación posee mandato nacional } \\
\text { para la Secretaría de Defensa del Consumi- } \\
\text { dor-SEDECO, no así para los municipios } \\
\text { que no están obligados a adherirse, es vo- } \\
\text { luntaria. }\end{array}$ \\
\hline
\end{tabular}




\begin{tabular}{|c|c|c|}
\hline \multirow{10}{*}{ 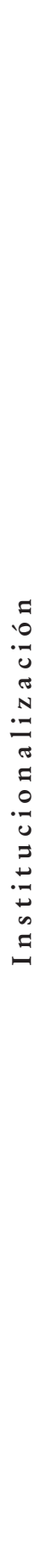 } & $\begin{array}{l}\text { Todas las comunidades autónomas cuentan } \\
\text { con su Oficina Territorial de Consumo, y } \\
\text { en los ayuntamientos están habilitadas las } \\
\text { OMIC. }\end{array}$ & $\begin{array}{l}\text { De los } 250 \text { municipios solo } 23 \text { municipalida- } \\
\text { des se hallan adheridas al Sistema Nacional } \\
\text { Integrado de Protección al Consumidor y } \\
\text { poseen oficinas de atención al consumidor } \\
\text { habilitadas. }\end{array}$ \\
\hline & \multirow{4}{*}{$\begin{array}{l}\text { Secretaría General de Sanidad y Con- } \\
\text { sumo, le corresponde la promoción de la } \\
\text { política de consumo mediante la propuesta } \\
\text { de regulación, en el ámbito de las compe- } \\
\text { tencias estatales, que incida en la protección } \\
\text { y la promoción de los derechos de los con- } \\
\text { sumidores y usuarios; el establecimiento e } \\
\text { impulso de procedimientos eficaces para la } \\
\text { protección de los mismos; la cooperación } \\
\text { institucional interterritorial en la materia, } \\
\text { así como el fomento de las asociaciones } \\
\text { de consumidores y usuarios y el apoyo al } \\
\text { Consejo de Consumidores y Usuarios. }\end{array}$} & $\begin{array}{l}\text { Ministerio de Industria y Comercio. Se- } \\
\text { cretaría de Defensa al Consumidor-SEDE- } \\
\text { CO, Autoridad de Aplicación en el ámbito } \\
\text { Nacional de la Ley de Defensa del Consu- } \\
\text { midor y el Usuario y de las demás leyes y } \\
\text { reglamentos que rigen la materia. }\end{array}$ \\
\hline & & Asociación de consumidores. \\
\hline & & $\begin{array}{l}\text { Instituto Nacional de Alimentación y } \\
\text { Nutrición-INAM, MSPyBS. }\end{array}$ \\
\hline & & \multirow{2}{*}{$\begin{array}{l}\text { Instituto Nacional de Tecnología y Nor- } \\
\text { malización y Metrología-INTN presta } \\
\text { servicios a consumidores, industrias, co- } \\
\text { mercio y servicios, mediante investigación } \\
\text { y asistencia técnica, normalización, certi- } \\
\text { ficación y metrología, con un enfoque de } \\
\text { responsabilidad social y sostenibilidad. } \\
\text { Convenio con Asociación Española de } \\
\text { Normalización y Certificación (AENOR) } \\
\text { de España }\end{array}$} \\
\hline & \multirow{2}{*}{$\begin{array}{l}\text { Cuenta con una Agencia Española de } \\
\text { Consumo, Seguridad Alimentaria y Nu- } \\
\text { trición, que integra y desempeña en el } \\
\text { marco competencial de la Administración } \\
\text { General del Estado las funciones relaciona- } \\
\text { das con la promoción y el fomento de los } \\
\text { derechos de los consumidores y usuarios } \\
\text { en bienes y servicios, así como la seguridad } \\
\text { alimentaria y la nutrición saludable }\end{array}$} & \\
\hline & & \multirow{3}{*}{$\begin{array}{l}\text { Secretaría del Ambiente-SEAM, encarga- } \\
\text { da del ordenamiento ecológico y del am- } \\
\text { biente en general, para la mejora de condi- } \\
\text { ciones de vida de los todos sectores de la } \\
\text { sociedad paraguaya y garantizar condicio- } \\
\text { nes de crecimiento económico, equidad so- } \\
\text { cial y sustentabilidad ecológica }\end{array}$} \\
\hline & $\begin{array}{l}\text { Dirección de Consumo Territorial, en las } \\
\text { comunidades autónomas. }\end{array}$ & \\
\hline & $\begin{array}{l}\text { Ayuntamientos, a través de la Oficina } \\
\text { Municipal de Información al Consumi- } \\
\text { dor-OMIC. }\end{array}$ & \\
\hline & $\begin{array}{l}\text { Unión Europea, donde } 28 \text { países poseen } \\
\text { acuerdos para la Defensa del Consumidor. } \\
\text { Funciona como una asociación entre la } \\
\text { Unión Europea (UE), sus países miembros } \\
\text { y sus ciudadanos. Se basa en principios fun- } \\
\text { damentales del Tratado de Funcionamiento } \\
\text { de la Unión Europea (TFUE) }\end{array}$ & $\begin{array}{l}\text { MERCOSUR, Comité Técnico n. }{ }^{\circ} 7 \text { órga- } \\
\text { no subordinado a la Comisión de Comer- } \\
\text { cio del MERCOSUR (CCM) y que reúne } \\
\text { a los órganos nacionales de defensa del con- } \\
\text { sumidor de los Estados Partes'. Su función, } \\
\text { controlar y monitorear las relaciones de } \\
\text { consumo; educar, asesorar y brindar al con- } \\
\text { sumidor la información necesaria para que } \\
\text { tenga un consumo eficiente y responsable a } \\
\text { través de programas y planes y basados en } \\
\text { la normativa que lo legisla. }\end{array}$ \\
\hline
\end{tabular}




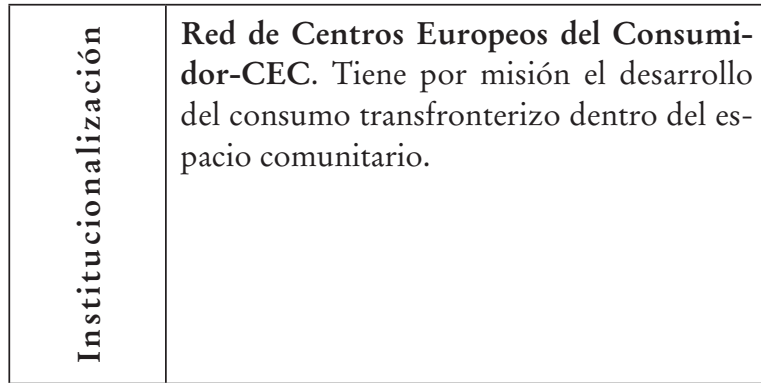

MERCOSUR, con ECONORMAS, Programa de Apoyo a la Profundización del Proceso de Integración Económica y Desarrollo Sostenible del MERCOSUR, con apoyo de la UE. Comienza en 2009, con la Comisión de las Comunidades Europeas y el MERCOSUR (Argentina, Brasil, Paraguay, Uruguay) del Grupo Mercado Común del Sur.

\begin{tabular}{|c|c|c|}
\hline \multirow{5}{*}{$\begin{array}{l}\tilde{J} \\
0 \\
0 \\
0 \\
0 \\
0 \\
0 \\
0\end{array}$} & $\begin{array}{l}\text { A cargo de: } \\
\text { Comunidades autónomas y ayunta- } \\
\text { mientos } \\
\text { Fundaciones que colaboran en el pro- } \\
\text { ceso de capacitación y formación, en } \\
\text { línea, con aportes didácticos y activi- } \\
\text { dades para maestros, estudiantes y fa- } \\
\text { milias. }\end{array}$ & $\begin{array}{l}\text { A cargo de: } \\
\text { SEDECO. Formula, realiza y fomen- } \\
\text { ta programas de educación e informa- } \\
\text { ción al consumidor, a través de medios } \\
\text { masivos de comunicación y de otros } \\
\text { mecanismos disponibles. Sus acciones } \\
\text { llegan a grupos estudiantiles, asociacio- } \\
\text { nes de consumidores, funcionarios de } \\
\text { municipios encargados de la Oficina de } \\
\text { Atención al Consumidor. }\end{array}$ \\
\hline & \multirow{2}{*}{$\begin{array}{l}\text { Escuelas, colegios e institutos, la } \\
\text { Ley dispone niños y jóvenes en edad } \\
\text { escolar, de forma transversal. Es de } \\
\text { abordaje continuo, como contenidos } \\
\text { curriculares, forma parte del Plan Edu- } \\
\text { cativo Institucional; se ejecuta a través } \\
\text { de Proyectos con los ayuntamientos, } \\
\text { oficinas de información al consumidor } \\
\text { de los municipios, fundaciones y servi- } \\
\text { cios territoriales. Por medio de empre- } \\
\text { sas públicas y privadas. }\end{array}$} & $\begin{array}{l}\text { Municipios adheridos, realizan accio- } \\
\text { nes con el apoyo técnico de SEDECO, } \\
\text { a estudiantes de colegio. }\end{array}$ \\
\hline & & $\begin{array}{l}\text { Escuelas y colegios no contemplan en } \\
\text { sus currículos; Educación para el Con- } \\
\text { sumo, solo se puede incluir por ade- } \\
\text { cuación curricular EEB; plan Optativo } \\
\text { Bachillerato, o por Proyectos si la ins- } \\
\text { titución lo define en el PEI. }\end{array}$ \\
\hline & $\begin{array}{l}\text { Universidades: dictan cursos de For- } \\
\text { mación a nivel de Grado y Posgrado } \\
\text { (Especialización, Máster con titulación } \\
\text { propia). Poseen equipos de investiga- } \\
\text { ción relacionados al tema. Publicacio- } \\
\text { nes periódicas. Convenios con institu- } \\
\text { ciones, organismos y empresas para el } \\
\text { abordaje del tema consumo. }\end{array}$ & $\begin{array}{l}\text { Universidades: como actividades com- } \\
\text { plementarias; Tema de Extensión uni- } \\
\text { versitaria; Forma parte de Líneas de } \\
\text { Investigación. Posgrado: cursos con } \\
\text { temas afines. } \\
\text { Independiente: Investigaciones con } \\
\text { mayor énfasis en el ámbito del Dere- } \\
\text { cho. }\end{array}$ \\
\hline & & $\begin{array}{l}\text { MERCOSUR - ECONORMAS, La- } \\
\text { boratorio Tecnológico del Uruguay } \\
\text { (LATU) del Uruguay como Entidad } \\
\text { Ejecutora del Proyecto. Una de las lí- } \\
\text { neas de acción es Producción y Con- } \\
\text { sumo Sostenible (PCS), cuyas direc- }\end{array}$ \\
\hline
\end{tabular}




\begin{tabular}{|c|c|}
\hline $\begin{array}{l}\vec{u} \\
\tilde{\sigma} \\
\tilde{E} .0 \\
\dot{0} .0 \\
0 \\
\dot{H}\end{array}$ & $\begin{array}{l}\text { trices son producir utilizando menos } \\
\text { recursos naturales, minimizando los } \\
\text { residuos y promoviendo el consumo } \\
\text { de forma responsable y saludable. En } \\
\text { Py. desarrolló acciones con el sector de } \\
\text { producción. }\end{array}$ \\
\hline
\end{tabular}

\section{Conclusión}

Las experiencias analizadas llevan a concluir que la formación de los ciudadanos en educación para un consumo responsable en Paraguay es aún incipiente y hace necesaria una labor comprometida y coordinada entre instituciones para llegar justificadamente a todos los sectores sociales.

El resultado del análisis permite a la Universidad Nacional de Itapúa, institución con acabado prestigio, experiencia en materia educativa y acciones cooperativas a nivel nacional e internacional, ampliar más allá de talleres y charlas aisladas; le cabe definir escenarios educativos permanentes, con actores concretos para entablar profundos debates, serios análisis de las implicancias del consumo.

Educar para el consumo es sensibilizar a que los actos de consumo implican la destrucción de los recursos (Arana, 2015, p. 28), y representa un compromiso a lo que la universidad no se muestra insensible, sino que ha puesto siempre la voluntad político-educativa para cimentar la sociedad democrática ordenada como plantea Antonio Bernat.

Entonces pues, abordarlo es en sí mismo un compromiso que incumbe a la educación y a las instituciones que la ostentan; por ello seguidamente se plantea una praxis integrada.

\section{PLAN DE DESARROLLO, «EDUCACIÓN PARA EL CONSUMO RES- PONSABLE»}

Plantea el abordaje y la acción a partir de tres ejes y que a la vez son fines de la universidad: Formación, Investigación y Extensión; y responde al $3 .{ }^{\text {ER }}$ objetivo del estudio.

\section{Justificación}

El presente Plan se concibe como una herramienta práctica para la incidencia en la construcción de un pensamiento más crítico, solidario y responsable que servirá para modificar los esquemas operativos de la sociedad, desde la educación superior hacia la sociedad que lo envuelve, como medio de mitigar la inequidad y, por qué no decir, la pobreza que aqueja a un gran número de la población mundial.

\section{I. Dimensiones}

Educativa, Económica, Legal, Social-Antropológica. 


\subsection{Perspectivas}

Transversalidad en la malla curricular de las diferentes carreras. Inclusión como disciplina en los cursos de grado.

\subsection{Temporalización}

Año 2017-2020.

7.4. Iniciativas de empoderamiento y potenciación del Consumo responsable desde la UNI

- Declarar de interés institucional la Educación para el Consumo Responsable y lograr el allanamiento de otras instituciones y organismos a su reconocimiento y apoyo sostenido.

- Crear convenio con instituciones públicas y privadas nacionales y extranjeras para el delineamiento de acciones y desarrollo de actividades en Educación para el Consumo.

- Incentivar permanentemente la Formación, Investigación y Extensión universitaria en la temática de Educación para el Consumo sostenible.

\subsection{Objetivos generales y acciones a realizar}

El objetivo general del Plan de Desarrollo propone la Educación como un modo de conocer, formar e intervenir en la práctica del consumo responsable como vía para el logro de una vida más sana en todos los aspectos y de equilibrio con el medio, en una sociedad globalizada y muy comunicada, con participación directa de la Universidad en su entorno social.

- Diseñar y ejecutar acciones educativas desde la UNI enfocadas al consumo responsable, en forma conjunta con instituciones, organismos, organizaciones sociales y empresas, como ocupación real hacia la concreción de objetivos 2030 de Desarrollo Sostenible de las NN. UU.

- Favorecer la presencia de la Educación para el consumo en el ámbito universitario con valor agregado de servicios a la ciudadanía en materia de asesoramiento y educación. 


\section{FORMACIÓN}

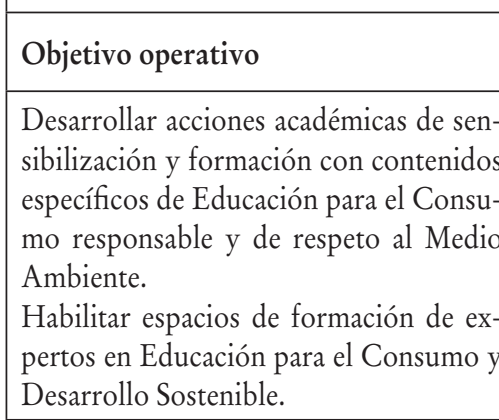

Integrar contenidos de Educación para el Consumo responsable y de respeto al Medio Ambiente a través de la ejecución de proyectos conjuntos, participativos, entre diversas disciplinas.

Interactuar en espacios de formación para niños con proyectos específicos en coordinación con el MEC e instituciones educativas de la EEB.

Fomentar a través de seminarios y cursos breves el conocimiento y la práctica del Consumo responsable para un Desarrollo Sostenible en ámbitos de la educación no formal.

Producir y difundir material informativo, breve, sobre Consumo Responsable y Desarrollo Sostenible.

\begin{tabular}{|l|l|} 
Línea de acción & Acciones específicas a realizar \\
\hline $\begin{array}{l}\text { Formación a docen- } \\
\text { tes en el área de Con- } \\
\text { sumo Responsable }\end{array}$ & $\begin{array}{l}\text { Realización de Cursos de Posgrado (Espe- } \\
\text { cializaciones y Máster) en Educación para } \\
\text { el Consumo, desde la Universidad en forma } \\
\text { conjunta con instituciones y/u organizacio- } \\
\text { nes. }\end{array}$ \\
$\begin{array}{l}\text { Formación a estu- } \\
\text { diantes de grado. } \\
\text { Formación a la socie- } \\
\text { dad en general, em- } \\
\text { pleados, funcionarios } \\
\text { de empresas e institu- } \\
\text { ciones. }\end{array}$ & $\begin{array}{l}\text { Elaboración y ejecución de proyectos inter- } \\
\text { disciplinarios, en las diferentes carreras. } \\
\text { Elaboración de talleres formativos para niños } \\
\text { siones de Ensenjuntamente con las Supervi- } \\
\text { trasversales. } \\
\text { Elaboración y ejecución de talleres formati- } \\
\text { vos, en convenio con instituciones y empre- } \\
\text { sas, con participación de la banca comercial y } \\
\text { la sociedad civil. } \\
\text { Elaboración de material informativo y de di- } \\
\text { fusión masiva para participantes de talleres y } \\
\text { medios de comunicación. } \\
\text { Elaboración de material informativo para las } \\
\text { disciplinas curriculares. }\end{array}$ \\
\hline
\end{tabular}

\section{INVESTIGACIÓN}

\begin{tabular}{|l|l|l|}
\hline Objetivo operativo & Línea de acción & Acciones específicas a realizar \\
\hline $\begin{array}{l}\text { Establecer como líneas de investigación } \\
\text { el Consumo Responsable y Desarrollo } \\
\text { Sostenible para las investigaciones en el } \\
\text { ámbito de la UNI. }\end{array}$ & $\begin{array}{l}\text { Incorporación como } \\
\text { líneas de investiga- } \\
\text { ción en las estableci- } \\
\text { das por el Rectorado } \\
\text { de la UNI. }\end{array}$ & $\begin{array}{l}\text { Inclusión de la Educación para el Consumo } \\
\text { como línea de investigación para docentes in- } \\
\text { vestigadores dependientes del Rectorado de la } \\
\text { UNI. } \\
\text { Composición de Grupo de Investigadores } \\
\text { ad hoc, para el abordaje de Educación para el } \\
\text { Consumo. } \\
\text { Realización de intervenciones en base a los } \\
\text { diagnósticos producto de las investigaciones. }\end{array}$ \\
\hline
\end{tabular}




\begin{tabular}{|c|c|c|}
\hline \multicolumn{3}{|l|}{ INVESTIGACIÓN } \\
\hline Objetivo operativo & Línea de acción & Acciones específicas a realizar \\
\hline $\begin{array}{l}\text { Incluir en los estudios e investigaciones } \\
\text { de Trabajo Final de Grado temas re- } \\
\text { lacionados con Consumo y Comercio } \\
\text { Justo, en las diversas carreras. }\end{array}$ & $\begin{array}{l}\text { Inclusión como te- } \\
\text { mática de investiga- } \\
\text { ciones en Trabajos } \\
\text { Finales de grado. }\end{array}$ & $\begin{array}{l}\text { Diseño de investigaciones de Trabajo Final de } \\
\text { grado que tengan como temática el Consumo } \\
\text { y desarrollo sostenible. } \\
\text { Elaboración de estudios de campo para niños } \\
\text { y adolescentes, de la EEB sobre temas relacio- } \\
\text { nados con el consumo y desarrollo sostenible, } \\
\text { con tutorías de estudiantes universitarios, por } \\
\text { periodos breves, trimestrales o semestrales. }\end{array}$ \\
\hline
\end{tabular}

\begin{tabular}{|c|c|c|}
\hline \multicolumn{3}{|l|}{ GESTIÓN Y EXTENSIÓN } \\
\hline Objetivo operativo & Línea de acción & Acciones específicas a realizar \\
\hline $\begin{array}{l}\text { Crear en el ámbito de la UNI la Oficina } \\
\text { de Desarrollo Sostenible. } \\
\text { Establecer como un eje de la política ins- } \\
\text { titucional el Consumo responsable. }\end{array}$ & $\begin{array}{l}\text { Gerenciamiento y se- } \\
\text { guimiento de temas } \\
\text { de Desarrollo Soste- } \\
\text { nible. (Consumo, In- } \\
\text { clusión, Género). } \\
\text { Encuentros con in- } \\
\text { terlocutores válidos } \\
\text { en cuanto al Con- } \\
\text { sumo responsable y } \\
\text { Desarrollo Sostenible }\end{array}$ & $\begin{array}{l}\text { Diseño de acciones para la organización de } \\
\text { actividades dentro y fuera de la UNI. } \\
\text { Contacto con las instituciones para el acerca- } \\
\text { miento a los temas de consumo responsable y } \\
\text { Desarrollo Sostenible. }\end{array}$ \\
\hline $\begin{array}{l}\text { Instrumentar normativas legales en el } \\
\text { seno de la Universidad para la ejecución } \\
\text { de acciones de Desarrollo Sostenible. }\end{array}$ & $\begin{array}{l}\text { Interés focalizado } \\
\text { hacia el Consumo } \\
\text { responsable como ac- } \\
\text { ción para el Desarro- } \\
\text { llo Sostenible. }\end{array}$ & $\begin{array}{l}\text { Declaración de interés institucional de pro- } \\
\text { yectos para el Consumo responsable y de De- } \\
\text { sarrollo Sostenible. }\end{array}$ \\
\hline $\begin{array}{l}\text { Difundir en entornos educativos y so- } \\
\text { ciales de legislaciones y normativas } \\
\text { vigentes a nivel nacional e internacional } \\
\text { sobre Consumo, Comercio Justo, Desa- } \\
\text { rrollo Sostenible. }\end{array}$ & $\begin{array}{l}\text { Incentivación al Vo- } \\
\text { luntariado. } \\
\text { Campañas masivas } \\
\text { para la sensibilización } \\
\text { social. }\end{array}$ & $\begin{array}{l}\text { Creación de grupos de voluntarios para las } \\
\text { campañas de Consumo responsable y Desa- } \\
\text { rrollo sostenible, integrada por estudiantes } \\
\text { universitarios, estudiantes de EEB, docentes e } \\
\text { interesados en conformar. } \\
\text { Establecimiento de la Semana del Consumo } \\
\text { responsable, con actividades de sensibiliza- } \\
\text { ción y educación. } \\
\text { Elaboración de talleres formativos para ni- } \\
\text { ños de la EEB, conjuntamente con las Super- } \\
\text { visiones de Enseñanza y Escuelas como temas } \\
\text { trasversales. }\end{array}$ \\
\hline
\end{tabular}




\begin{tabular}{|c|c|c|}
\hline $\begin{array}{l}\text { Gestionar convenios de cooperación } \\
\text { con instituciones públicas, privadas, } \\
\text { organismos de sociedad civil y empresas } \\
\text { para diseño y ejecución de proyectos } \\
\text { relacionados con el Consumo y Desa- } \\
\text { rrollo Sostenible. }\end{array}$ & $\begin{array}{l}\text { Dirigidas a: } \\
\text { - Formación } \\
\text { - Servicios } \\
\text { - Orientación, etc. }\end{array}$ & $\begin{array}{l}\text { Formación a la sociedad en general: } \\
\text {-Servidores públicos } \\
\text { - Funcionarios de empresas privadas } \\
\text { - Colectivos de la } 3 \cdot{ }^{a} \text { Edad, Discapacitados, } \\
\text { Niños, Mujeres. } \\
\text { - Policía Municipal. } \\
\text { - Academia de policía. } \\
\text { - Intendentes y secretarios de los Municipios. } \\
\text { - Formación de asesores jurídicos en materia } \\
\text { de Consumo. } \\
\text { Técnicas: } \\
\text { Charlas. } \\
\text { Seminarios. } \\
\text { Cursos breves/Diplomados, dictados por ex- } \\
\text { pertos de las instituciones que conforman el } \\
\text { convenio. }\end{array}$ \\
\hline $\begin{array}{l}\text { Diseñar con medios de comunicación, } \\
\text { Radio, TV, spots de sensibilización hacia } \\
\text { Consumo responsable. }\end{array}$ & $\begin{array}{l}\text { Campañas masivas } \\
\text { de sensibilización, } \\
\text { dirigidas a la sociedad } \\
\text { con convenios con } \\
\text { Radios, TV. }\end{array}$ & $\begin{array}{l}\text { Escribir, describir, grabar creativamente guio- } \\
\text { nes de las campañas de sensibilización, dirigi- } \\
\text { das a la sociedad, en lenguas oficiales. } \\
\text { Participación activa de niños, jóvenes y adul- } \\
\text { tos en los spots elaborados (artistas, deportis- } \\
\text { tas, escritores, etc.). }\end{array}$ \\
\hline $\begin{array}{l}\text { Hacer uso de la tecnología para la pro- } \\
\text { moción del Consumo responsable en el } \\
\text { segmento joven. }\end{array}$ & $\begin{array}{l}\text { Campañas virtuales } \\
\text { dirigidas a jóvenes y } \\
\text { creadas por jóvenes } \\
\text { con incentivos edu- } \\
\text { cativos. }\end{array}$ & $\begin{array}{l}\text { Creación de APP para móviles y ordenado- } \\
\text { res, gratuitas, dirigidas a usuarios jóvenes, por } \\
\text { estudiantes de la carrera de Informática, cuya } \\
\text { participación será a través de un concurso de } \\
\text { ideas y premiado. }\end{array}$ \\
\hline $\begin{array}{l}\text { Construir espacios, propios, de difusión } \\
\text { a través de las revistas institucionales }\end{array}$ & $\begin{array}{l}\text { Inclusión de escritos } \\
\text { y eventos sobre con- } \\
\text { sumo y en las revistas } \\
\text { de la UNI. } \\
\text { Uso de papel recicla- } \\
\text { do en la FaCyT y con } \\
\text { imprenta propia. }\end{array}$ & $\begin{array}{l}\text { Difusión de ideas, eventos, investigaciones } \\
\text { sobre consumo y desarrollo sostenible. } \\
\text { Creación de una imprenta institucional con } \\
\text { materia prima de papel reciclado. }\end{array}$ \\
\hline
\end{tabular}

\section{Bibliografía}

Alonso, L. (2005). La era del consumo. RIS, Madrid, Siglo XXI, 49, 23I-235.

Arana, J. María y De Castro, D. (coords.). (2015). Consumir sin consumirse. Educación para el consumo. Madrid: Ediciones Pirámide (Grupo Anaya, S. A.).

Berlanga, S. (20io). La educación del consumidor en el aula, en la familia y en la sociedad. Zaragoza: Mira Editores, S. A.

Bernal, C. A. (20Io). Metodología de la Investigación administración, economía, humanidades $y$ ciencias sociales ( $3{ }^{a}$ ed.). Colombia: Pearson Educación. Universidad de la Sabana. 
Cristoffanini, P. R. (2006). La cultura del consumo en América Latina. Sociedad y discurso. $A A U$, I0, 92-108.

Decreto del Poder Ejecutivo.$^{\circ}$ 2199, que Reglamenta la Ley 4974/2013 que crea la Secretaría de Defensa del Consumidor y el Usuario, de la República del Paragnay, 8 de setiembre de 2014.

Grupo Si(E)Te. (2007). Educación. Educación y Consumo. Universitaria, 2-I3. Publicación especial.

Hernández Díaz, J. M. (coord.). (20I4). Historia y presente de la educación ambiental. Ensayos con perfil iberoamericano. Salamanca: FahrenHouse.

Lara, G. y Colin, G. (2007). Sociedad de Consumo y Cultura Consumista, en Zygmunt Bauman. Argumentos $U A M x, 20,21 \mathrm{I}-2 \mathrm{I} 6$.

Ley 1334, 1998, de Defensa del Consumidor y Usuario. Biblioteca y Archivo Nacional del Congreso Nacional de la República del Paraguay, 30 de octubre de 1998.

Ley 4974, 2013, de la Secretaría de Defensa del Consumidor y el Usuario. Biblioteca y Archivo Nacional del Congreso Nacional de la República del Paraguay, 28 de agosto de 2013.

Paraguay. Secretaría de Defensa del Consumidor y el Usuario. sedeco. (20i5). Informe Ejecutivo de Gestión. Asunción: Enrique Bordón, Secretario.

Pnuma. (20II). Hacia una economía verde: Guia para el desarrollo sostenible y la erradicación de la pobreza - Sintesis para los encargados de la formulación de las políticas. www.unep. org/greeneconomy

Presentación de la Ley de Defensa del Consumidor en guaraní y suscripción de convenios con la Municipalidad de Coronel Bogado y la UNI. http://www.sedeco.gov.py/index.php/noticias/ presentacion-de-la-ley-de-defensa-del-consumidor-en-guarani-y-suscripcion-de-convenios-con-la-municipalidad-de-coronel-bogado-y?ccm_paging_p $=24$

Programa de la Naciones Unidas para el Medio Ambiente y el Desarrollo. Marco Decenal de Consumo y Producción Sostenible, roYFP.

Pujol, R. (1996). Cuaderno de Educación. Educación y Consumo. La formación del consumidor en el aula. Barcelona: Editorial Horsori. Universidad de Barcelona.

Universidad de Córdoba-España. (20II-20I2). Plan de Acción de Consumo Responsable y Comercio Justo.

\section{Incentivos para que el docente aborde tema Consumo en aula}

I- Que forme parte del currículo educativo

2- Formación y capacitación en el tema

3- Materiales didácticos

4- Apoyo de los estamentos comprometidos con el área.

5- Promoción de Educación en Consumo por SEdeco, Universidades y Asociación de docentes. 
